


\section{La estatua de sal, de Salvador Novo. Urbanismo e identidad homosexual en la ciudad de México, 1917-1921}

\section{The Statue of Salt, by Salvador Novo. Urbanism and homosexual identity in Mexico City, 1917-1921}

León Guillermo Gutiérrez

Alejandro Guadarrama Universidad Autónoma del Estado Morelos, México

Resumen: Salvador Novo (1904-1974), en su autobiografía La estatua de sal (1998), plasmó el acontecer de la vida homosexual en la ciudad de México en el período que abarca de 1917 a 1921. En este trabajo se pretende, en base a la narración de Novo, hacer un análisis de cómo, a pesar de ser una conducta transgresora, el homoerotismo era una práctica bastante extendida en los diferentes estratos sociales. La ciudad de México no sólo se presenta como escenario, los espacios públicos y privados son donde las acciones se desarrollan, su papel es protagónico en la novela. De ahí que también se analice cómo el urbanismo determina y condiciona la construcción de la identidad homosexual. Así vemos que el homosexual se convierte en agente de la inestabilidad en la estructuración de la red de relaciones sociales, y participa en la reconfiguración de los lugares de una ciudad.

Palabras clave: La estatua de sal, Salvador Novo, identidad, homosexual, urbanismo.

Abstract: Salvador Novo (1904-1974), in his autobiography The Statue of Salt (1998), captured the events of the homosexual life at Mexico City from 1917 to 1921 . This work is intended, based of Novo's narration, to do an analysis of how, despite being a transgressive behavior, the 
homoeroticism was a fairly widespread practice in different social strata. Mexico City not only arises as a scenario, public and private spaces where actions are developed, it's role is starring in the novel. For that we analyze how the urbanism determines and conditions the construction of gay identity. Thus we notice that the homosexual becomes agent of instability in the structuring of the network of social relations, and participates in the reconfiguration of the places of a city.

Palabras clave: The Statue of Salt, Salvador Novo, identity, homosexual, urbanism.

Recibido: 10 de octubre de 2017 Aceptado: 3 de marzo de 2018

Tniciaremos con el concepto de ciudad y su importancia para 1 quienes las habitan, así como el contexto histórico y urbano de la ciudad de México en esa época. Aristóteles, en el Libro III de Política, señala: "La ciudad, en efecto, es una colección de ciudadanos" (197), y más adelante: "un conjunto de hombres habitantes de un mismo lugar" (199). En las dos oraciones vemos que, para que se dé la existencia de la ciudad, se requiere de la voluntad de hombres para habitar en un espacio, voluntad que Aristóteles llamará "forma de gobierno" (199). No hay que olvidar que el concepto se refería a ciudades-estado, conocidas bajo la denominación "Polis", y que eran el centro político, cultural y ciudadano de la sociedad griega. Pero en todas las ciudades de las civilizaciones antiguas con alto grado de desarrollo, desde un principio, el urbanismo fue de suma importancia; por eso, las ciudades se construyeron bajo un plano en el que se consideraban, además de las casas particulares donde habitaban los ciudadanos, los edificios y lugares públicos como templos, plazas, foros y mercados. En el trazo de las ciudades, la red bajo la que se constituía la vinculación de las edificaciones era la calle, espacio urbano por excelencia, en el que las personas transitan y dotan de vitalidad a la ciudad. 
Con el tiempo, las ciudades han crecido a un ritmo exponencial impresionante, pero se ha conservado en su esencia el concepto y uso de los espacios públicos y privados. $\mathrm{Y}$ es en estos complejos urbanos donde surgen nuevas identidades vinculadas, algunas por afinidades e intereses comunes, aún a pesar de que los espacios de interacción social sean habitados por "extrańos". Esto da paso a pensar en la construcción social de la ciudad como una superposición de paradojas complejas que impiden verla como una resolución general, ya que a pesar de que en la ciudad se establecen ciertas delimitaciones de configuración, siempre se crean áreas estratégicas de reconfiguración. Por lo que Zimmerman explica que: "Las ciudades son estriadas, limitantes. Pero por su constitución misma, ellas reconstruyen superficies lisas que pueden ser lugares de resistencia y formación de nuevas estrategias para nuevas configuraciones y texturas de espacio" (Zimmerman, 2003: 39). Es decir, dentro de la planeación estructurada de la ciudad, los desarrollos de la urbanidad son los que llenan a los complejos urbanos de inestabilidad.

Las ciudades se vuelven paradojas que se reconocen precisamente porque nadie está en su lugar sin dejar de pertenecer a un lugar claramente establecido para el funcionamiento de la ciudad. Por lo tanto, la inestabilidad es la estructuración de la red de relaciones sociales que, aunque pareciera líquida, sigue desembocando en un mismo cause que da cierta identidad insipiente de comunidad. Los espacios urbanizados no tienen una delimitación tangible, sino invisibilidades espaciales que viven sólo dentro de la misma ciudad y la individualidad de los habitantes, los cuales reconfiguran sus sitios de acuerdo a los roles jugados por las circunstancias que desnudan las percepciones de las dificultades de los lugares en la ciudad. De esta manera se puede constatar que, a falta de concreciones, se tocan confusiones que ritualizan la vida cotidiana de la urbanidad. 
Por estos motivos, la ciudad se nos presenta como una complejidad llena de variantes que expresan subjetividades y sentimientos de los individuos, es un espejo que refleja perfectamente un mosaico indescifrable de un todo que está fragmentado sólo mientras se mantiene unido. "La ciudad es reflejo de quienes la habitan, de su orden político y de su modelo de sociedad. En ella revelamos nuestra identidad más íntima, el amor, el respeto o la indiferencia" (Naime, 2007: 116). Por tanto, la urbe revela lo que se quiere ver, pero esconde lo que se quiere observar, de tal forma la ciudad necesita de una profundidad que admire su superficie, y de una redirección de la gloria de sus banalidades y sus prejuicios. Para el sociólogo urbano Ezra Park:

La ciudad y el entorno urbano representan para el hombre la tentativa más coherente y, en general, la más satisfactoria de recrear el mundo en que vive de acuerdo a su propio deseo. Pero si la ciudad es el mundo que el hombre ha creado, también constituye el mundo donde está condenado a vivir en lo sucesivo. Así pues, indirectamente y sin tener plena conciencia de la naturaleza de su obra, al crear la ciudad, el hombre se recrea a sí mismo (Park, 1999: 115).

La construcción de la ciudad por el individuo es la retroalimentación de la construcción del individuo por la ciudad, es la creación de una ley que comprueba la existencia de seres íntimamente extrańos, perdidos en la inconsciencia que detiene una asimilación ignorada y cambiada por el placentero drama de no ser olvidado por un lugar, por un tiempo, por un espacio y por una sociedad que ya no crea exclamaciones, sino interrogantes e intrigas de personalidades que se aferran a una moda para no morir, como la ciudad se aferra a la modernidad para no desaparecer. Los temores de la ciudad y sus habitantes se conjugan en suposiciones de un 
eterno presente, de un pasado con demasiada influencia social y cultural, y de un futuro que aprisiona sin existir.

Los individuos transforman la ciudad, creando nuevos espacios de conveniencia social que van más allá de los grupos jerárquicos institucionales. En palabras de Emilio Martínez:

El individuo puede moverse entre estos grupos y rehuir de ese modo las constricciones del grupo primario (de la familia, del vecindario, de lo estrictamente local). Esto otorga al ambiente urbano una diversidad social y cultural que estimula y educa al ciudadano en nuevos patrones de comportamiento, algunos de ellos desviados (Martínez, 1999: 33).

La diversidad social y cultural es lo que nutre la dinámica cotidiana dentro de la ciudad, la cual pareciera tan gastada y simple que termina con el ocaso de cada día, y sin embargo al amanecer renace para reinventar los miedos y deseos de los urbanitas. Ejemplo claro de esto, es la ciudad de México, la cual en la década que va de 1910 a 1920 sufrió un sinfín de modificaciones, todas ellas derivadas de factores como la Revolución Mexicana, de los nuevos modos de vida social con el advenimiento del cine, ritmos musicales, modas de vestir, el automóvil, etc., que trajeron como consecuencia cambios en las costumbres de sus habitantes. También se inició la primera gran migración del siglo XX hacia la capital del país. Otro de los motivos fueron los centros de estudios como la Escuela Nacional Preparatoria y la Universidad Nacional de México. Pero también es cierto que el epicentro urbano de la ciudad se concentraba en lo que ahora se conoce como centro histórico, lo que hacía que la densidad poblacional se moviera en un radio geográfico no muy grande.

Salvador Novo, nació en 1904, en la Ciudad de México. A causa de la Revolución la familia se trasladó a Torreón, Coahuila en 1910, y Novo, junto con su familia llegó a la ciudad de Méxi- 
co siete años después. Ingresó a la Escuela Nacional Preparatoria, para después estudiar en la Universidad, donde no concluyó sus estudios de Leyes. Según narra, la familia se asentó en la colonia Guerrero: "entonces poblada de clase media decente y con aspiraciones" (2002: 71). Otra parte de sus familiares vivían en la colonia San Rafael, de carácter aristocrático.

Novo, a lo largo de su autobiografía, escrita en 1945, pero que salió a la luz hasta 1998, se dio a la tarea de describir a la ciudad y a un cierto tipo de habitante en particular: el homosexual; lo que hace que también sea un documento valioso para los antropólogos urbanos y otros especialistas. La novela también nos recuerda los libros de viaje del siglo XIX, en que los autores hacían de la crónica de lo visto y vivido una verdadera delicia. Vale la pena recordar que Novo fue un gran cronista como prueban los tomos de La vida en México, que va del período presidencial de Lázaro Cárdenas a Díaz Ordaz. Así que podemos ver su autobiografía como una verdadera crónica de lo visto y vivido en la ciudad de México, desde una perspectiva particular: la homosexualidad.

La primera descripción que hace de la ciudad es una estampa magnífica del vestir de la clase masculina acomodada, lo que presenta a un Novo frívolo, ávido de ser uno más de los jóvenes vestidos a la última moda:

Los primeros días en México se me llenaban de infinitas, gratas sorpresas. La ciudad grande, limpia, de clara atmósfera, dejaba aún admirar sus viejos edificios y sus construcciones porfirianas todavía no profanados por la piqueta ni lanzados a los rascacielos. El tránsito era moderado, como el número de habitantes, de peatones seguros y lentos en recorrer las calles y en cruzarlas sin prisas ni temores. Por la avenida Madero -en cuyas tiendas Regal y High Life, o lo que después se convertiría en High Life- me llevaron a comprar unos soñados zapatos con blanca suela de hule. Paseaban su distinguida, decadente indolencia, los fifies que multiplicaban 
como muñecos de escaparate los atrevidos modelos BucherBros, la sastrería que dictaba la elegancia masculina en Bolívar y Madero (Novo, 2002: 73).

Aunque Salvador Novo llega muy joven a México, ya había tenido sus primeros escarceos homoeróticos. Según cuenta, abandonó los estudios y se dio a la vida de vagancia y, sobre todo, a la experimentación como homosexual. Monsiváis escribe: "en Novo la homosexualidad es impulso, estímulo primordial, seña de identidad" (2002a: 12). De ahí que la novela esté poblada de aventuras, peripecias, propias y ajenas, sin tener reparo en decir los nombres de cada uno de ellos, así como sus apodos y hasta sus gustos sexuales. Esto nos lleva a descubrir la creación de la identidad de un nuevo habitante amparado por cierta invisibilidad y anonimato que ofrece la ciudad, en este caso del homosexual. Aún estudiante apunta: "Entre la escuela y la casa, se extendía larga, la seductora, desconocida ciudad, convocándome a recorrerla, a sentir en ella el disfrute de mi inédita libertad" (2002: 76). En la oración vemos en primer plano a la ciudad, como un personaje atrayente por sus atributos seductores y desconocidos, espacio en el que se desea explorar la libertad, y qué otra si no es la sensualidad. Cabe señalar que Novo no pertenecía a los homosexuales que tratan a toda costa de mostrarse con un comportamiento masculino, por el contrario, Novo se esmeraba en su acicalamiento afeminado:

Por las mañanas, despertaba temprano, no tanto porque no me alcanzase el tiempo para llegar con puntualidad a la primera clase; sino para poder disfrutar, antes que nadie, del hermoso baño, y para poderme aplicar, sin que nadie lo viese ni me lo pudiera reprochar, todas las cremas y todos los polvos de sus pletóricas vitrinas; para pulir mis uñas con sus bellas herramientas de marfil y llegar a la escuela lleno de vanidad, resuelto a llamar la atención y a conquistar la envidia admirativa de mis compañeros (2002: 84). 
Pronto comienza a depilarse las cejas, esperando que alguien descubriera sus "aptitudes para trabajar en el cine". Aquí vemos que el cine ya es parte de la educación sentimental de la época; actores y actrices serán el modelo a seguir.

Según narra Novo, quien lo introduce en el submundo homosexual es Ricardo Alessio Robles, pianista que se hacía llamar Clarita Vidal y hermano del Ministro de Industria Miguel Alessio Robles. Y efectivamente, será a partir de ese encuentro cuando Novo vive aventuras y desventuras. En el cuarto que servía de estudio a Clarita Vidal, conoce y se enamora de Arturito, chofer de los camiones de pasajeros en la colonia Roma, que lo hacía: "aguardar largas horas en la esquina de Tacuba y Brasil el regreso de su vehículo, para tomar asiento a su lado y aspirar con un deleite retrospectivo y promisor las emanaciones de la gasolina junto a su cuerpo" (2002: 95). Salvador Novo ya estaba acondicionado a este tipo de atracciones considerando que su primera experiencia sexual fue con Emilio, el chofer de la casa que emanaba olor a gasolina.

La amistad con Clarita Vidal y su propensión por conocer este mundo nuevo sin restricciones ni prejuicios, lo va a llevar a descubrir una red de personajes homosexuales de todas las esferas sociales:

Clara me llevaba todos los días a presentar con gente diversa y pintoresca, a conocer sus casas y sus medios bizarros: a la vecindad en una de cuyas accesorias el bailarín Pedro Rubín dormía aún a la una de la tarde sobre el suelo, después de una noche de orgía que relataba con todo género de detalles; a otra vecindad de la calle Luis Moya que era una especie de casa de citas masculina, regenteada por un mesero cuyo amante dormía a todas horas en la gran cama de madera llena de lazos azules, y animada a ratos por la presencia de un español muy viejo que lucía una larga cabellera, se hacía llamar Carmen y se marchaba por las noches a servir en un burdel de mujeres (2002: 95). 
Este cuadro es en sí mismo una imagen por demás reveladora de la extendida comunidad homosexual. Por un lado, llama la atención el aparente desenfado en el que vivían y, por otro, la gran demanda de casas dedicadas a la prostitución de varones, así como la proliferación de alcahuetes como la Golondrina, "eficaz surtidor de muchachos". Novo va trazando el mapa de la ciudad, la nomenclatura de las calles, cines y, claro, de sus personajes. También es quien da a conocer el código de identidad entre los homosexuales. Así, escribe: "Descubierto el mundo soslayado de quienes se entendían con una mirada, yo encontraba aquellas miradas con sólo caminar por la calle: la avenida Madero, por la que entonces la gente paseaba lentamente todas las tardes" (2002: 102). La mirada es la contraseña inequívoca por la que hombres se reconocerán, código sólo identificado entre ellos. Novo traza un urbanismo homosexual, en el que "los homosexuales frecuentaban lugares mixtos: cantinas populares y cabarets del actual Centro Histórico, como el Madreselva o Los Eloínes" (Boivin, 2011: 157).

Es importante aclarar que aunque hay registros de la homosexualidad a través de la historia, es la época capitalista y la aparición de los diversos elementos de urbanización y modernización del siglo XX como "la extensión del trabajo asalariado, la expansión de las ciudades y las condiciones de anonimato" (Boivin, 2011: 148), los cuales contribuyeron para que aparecieran nuevas instituciones y nuevos patrones de comportamiento que "favorecieron la aparición y visibilización de sujetos sexuales diferenciados en términos de prácticas y significados" (Boivin, 2011: 148). Además, se debe tomar en cuenta la reconceptualización de las clases sociales para entender la construcción de la identidad homosexual en la ciudad de México de las primeras décadas del siglo XX, ya que para la década de 1920 "es inevitable la presencia de aquellos gays que, por su dinero o su prestigio, se eximen en alguna medida del acoso" (Monsiváis, 2002a: 90). Es decir, mientras los gays de las clases 
populares tienen que soportar todo tipo de humillaciones, delaciones, señalamientos y discriminaciones, que imposibilitan que sus voces pudieran tener alguna acción dentro de su sociedad, "los gays con dinero y/o prestigio establecen el ghetto, en el universo subterráneo que halla con rapidez códigos, lenguaje y 'zonas morales'” (Monsiváis, 2002a: 90).

Es en la ciudad en donde se reúnen todos los elementos políticos, económicos y sociales, por lo que se corresponde con sus habitantes en la construcción cultural de las identidades, las cuales se vuelven múltiples y encuentran su conjunción en el concepto de ghetto. Además los pertenecientes al ghetto establecen códigos de identidad singulares, ya que "estos sectores, a la vez naturales y sociales, constituyen ámbitos diferenciados por sus costumbres, por sus valores, por sus universos de discurso, por sus normas de decencia y de presentación, coloreando el ambiente urbano de un modo muy particular” (Martínez, 1999: 33). Por lo que según Monsiváis:

En las penumbras se conforma el ghetto. Por eso el verbo que se usa como seńal es entender, esto es, saber con exactitud el significado del otro comportamiento. El entendido domina los secretos: quienes son sus semejantes, en qué consisten las reuniones, cuál es el idioma secreto, por qué se asiste a los bailes anuales como si se fuera a una batalla, quienes son los que se ocultan de todos menos de unos cuantos, aquellos que, porque les consta, los delatan (Monsiváis, 2002a: 92).

En la narración de Novo, sólo tienen nombre propio y apodo los que pertenecen al ghetto, los que se reconocen entre sí como homosexuales. "En la mecánica del ghetto, común a todas las minorías acosadas, el vituperio de sí y de los semejantes mediatiza el filo de exterminio de los epítetos machistas" (Monsiváis, 2002a: 29). Se puede decir que los otros personajes son cosificados bajo otra 
taxonomía: muchachos, choferes, cadetes, cobradores, meseros, jovencitos. Monsiváis señala: "En La estatua de sal, un tema básico es el ingreso al ghetto homosexual [...] y gracias al método de las 'concesiones sexuales' del personaje, el ghetto va entregando sus secretos, sus manías preciosistas, su agudeza para el apodo" (2002a: 39). Es decir, en el ghetto se encuentran establecidas ciertas formas de comportamiento que influyen en la cotidianidad de los integrantes -en sus costumbres, su personalidad y hasta en su lenguaje- y, por tanto, en la psique individual derivada de la potenciación de la psique colectiva. Todo con el objetivo de mantener la cohesión del grupo aislado o segregado; por lo que se puede decir que:

Cada uno de estos grupos segregados trata de imponer inevitablemente a sus miembros algún tipo de aislamiento moral con el fin de mantener la integridad vital del grupo. En la medida que la segregación se convierte para ellos en un medio para un fin, puede afirmarse que cada pueblo y cada grupo cultural crean y mantienen su propio ghetto (Park, 1999: 111).

Justo es esta segregación la que Novo logra captar de manera eficiente para narrar su vivir en paralelo, en el cual pasa de un mundo natural a otro, debido a su posición de pertenencia, mundo contiguo dentro de la ciudad, sin la posibilidad de exterminar uno de esos mundos, ya que se convierten, por su naturaleza limítrofe, en dependientes uno del otro. Esta posición es la que Novo vive, siente y expresa, para mostrar la seducción de la efervescencia juvenil homoerótica de la época, habilitada por un estilo de vida desde los espacios segregados.

Lo que Novo desarrolla en su autobiografía es una comprobación de que estos procesos de segregación -que desde los márgenes hacen una congregación formando ghettos, los cuales establecen los mundos contiguos y separados pero que tienen un carácter limítrofe- tienden a "conferir a la vida urbana un carácter superficial 
y casual, a complicar las relaciones sociales, y a producir nuevos y divergentes tipos de individuos. Esto introduce al mismo tiempo un elemento de azar y de aventura que se añade a la excitación de la vida urbana y le otorga un atractivo particular para los temperamentos jóvenes y fogosos" (Park, 1999: 33). Por eso, no resulta raro que donde más se manifiesta el humor es en el desfile de apodos impuestos por las características físicas o por las conductas de los interfectos, de ahí los apelativos: Clarita Vidal, Chucha Cojines, la diosa de Agua, la Perra Collie, la Nalga que Aprieta, la Tamales, la Virgen de Estambul, Suzuki, la Golondrina, la Pedo Embotellado, la Pitonisa, y una pareja conocida como Nelly Fernández y su Chingada Madre. Por supuesto, el escarnio y la mofa van implícitos. Al respecto, Monsiváis escribe: "Es el recordatorio incesante de la medida del menosprecio de los de afuera; el 'travestismo verbal' es obligatorio porque lo más próximo a la identidad de los 'raritos' es la identidad femenina por contagio" (2002a: 39-40).

Otro punto a considerar es el impacto revolucionario y sus consecuencias que provocaron que la ciudad de México sirviera de albergue a nuevos habitantes y formas de vida. En esta época de reacomodo político, económico y social, la ciudad sufrió transformaciones. En un periodo de tiempo que arranca desde 1917 hasta entrados los años veinte, la narración de Novo cobra una gran relevancia histórica al llevarnos de la mano por un sinnúmero de calles, vecindades, estudios, comercios, cines, casas principescas. Para entender de manera más profunda el fenómeno de la homosexualidad en la ciudad de México en esta época revolucionaria, Carlos Monsiváis, señala:

La Revolución con su demolición temporal del pudor, en algo 'sexualiza' el país [...] Sobre todo, la Revolución debilita el peso absoluto de las prohibiciones morales. [...] Por eso, entre las consecuencias de la Revolución, se halla también, la certidumbre en muy amplios sectores, de la asombrosa inutilidad de la represión 
íntima. [...] En una década se pulverizan nociones semifeudales de la Decencia [...] El proceso no se da de modo parejo desde luego, pero en la capital su vigor afianza los espacios de tolerancia (2002a: 18-19).

Salvador Novo vivió en estudios que sólo a veces compartía, lo que le daba mayor libertad. Del último que da cuenta, y que también es al final de la novela, se encontraba en la calle de Brasil, próximo al Departamento de Tránsito, espacio donde establece un acuerdo con su amigo Pepe Alcalde: "Y empezamos el trueque: yo le pasaba los choferes y cobradores que accedían a ello, y él llevaba al cuarto a los cadetes" (2002: 120).

Todo lo anterior nos conduce al descubrimiento de la identidad del homosexual en esos tiempos. Los estudios narratológicos establecen como elementos en la configuración narrativa del personaje, entre otros, el nombre y atributos, así como las acciones y el discurso del personaje. En la novela, el correspondiente al nombre, en la mayoría de las veces es sustituido por el sobrenombre femenino; las acciones siempre se corresponden con encuentros y aventuras de índole homoerótico, y el discurso está completamente permeado por el impulso de la homosexualidad. Así vemos que el homosexual se convierte en agente de la inestabilidad en la estructuración de la red de relaciones sociales, y participa en la reconfiguración de los lugares de una ciudad.

Novo, sin proponérselo, ofrece por medio de su autobiografía un urbanismo homoerótico, y proporciona los elementos necesarios para descubrir los códigos de construcción de la identidad del homosexual en la ciudad de México de 1917 a 1921, volviéndose una voz que invalida "el mito de la invisibilidad y aislamiento del homosexual antes de los años 1970" (Boivin, 2011: 149).

Novo trata el significado de lo homosexual de manera encarnada, pero especificando de manera sutil la profundidad de cada una de las características del concepto de homosexualidad, el cual 
"unifica un conjunto de prácticas sexuales que tienen en común la elección de un mismo objeto sexual, es una construcción discursiva, social y espacial" (Boivin, 2011: 150). En otras palabras, en el texto de Novo se desnudan explícitamente los elementos con los que convive la comunidad gay de la época, los cuales delimitan, pero también a su vez construyen, la identidad homosexual dentro de la ciudad de México de las primeras décadas del siglo XX.

Según Boivin, "la aparición y el desarrollo de lugares específicos para una población homosexual es concomitante de la creación de una identidad homoerótica y de la definición de unos modos propios de sociabilidad" (2011: 158) En la pluma de Salvador Novo se puede observar lo que Boivin establece, ya que entre las líneas de La estatua de sal salen los nombres de los edificios, los establecimientos, las casas y las calles de la ciudad que servían de lugares de conformación y esparcimiento para los ghettos homosexuales.

Lo memorable que tiene la conformación del ghetto homosexual según Monsiváis es "la lista de personajes públicos, secretarios de estado, escritores, artistas, políticos” (2002a: 90). Estos personajes pertenecientes sobre todos a "miembros de familias porfirianas o... de la élite revolucionaria” (Monsiváis, 2002a: 91) quedan solidificados al voltear las páginas de La estatua de sal, y son expuestos ante la mirada del lector, revelando los cargos élite que permitieron que la socialización homoerótica se comenzara a expandir y a denotar en diversos espacios públicos de la ciudad. De esta forma, los homosexuales de la época empezaron a ocupar "el espacio urbano de diversas maneras, llegando a constituir territorios donde aliar reconocimiento, seguridad y anonimato" (Boivin, 2011: 148).

La autobiografía de Novo gira alrededor de su persona y su condición homosexual, sin embargo, el texto va más allá de él y su orientación sexual, las letras fluyen recorriendo su carne, pero pronto se esparcen entre las calles de la ciudad de México revelando lugares, personajes, preferencias, sistemas políticos, económicos 
y condiciones sociales que giran en torno a la construcción de la identidad homosexual dentro de la ciudad, aunque desde las marginalidades a las que se enfrenta el ghetto homosexual; no obstante, es esta condición limitante la que paradójicamente potencializa la construcción de identidad, ya que al ser tan costosa en lo psíquico y lo social la disidencia, acrecientan su valor los actos sexuales y el idioma del ghetto (Monsiváis, 2002a: 91).

Aunque La estatua de sal es la estatua petrificada que se muestra sin censura en primera instancia al propio autor del libro, en un mensaje claro de Novo a Novo, pronto las letras ocasionan la ruptura de la solidificación de la estatua y los granos de sal se esparcen para revelan un valor que no sólo se muestra desde el campo autobiográfico y literario, sino que revelan un valor estético, histórico, político y social, además de retratar un mapa homoerótico de la ciudad y mostrar cómo se construía la identidad homosexual en el México de principios del siglo XX.

\section{Bibliografía}

Aristóteles, 1976, Política, Porrúa, México.

Boivin, Renaud, 2011, "De la ambigüedad del clóset a la cultura del gueto gay: género y homosexualidad en París, Madrid y México", La ventana, núm. 34, pp. 146-190. Disponible en: http://www.redalyc.org/pdf/884/88422488008.pdf (Consultado: 20/IX/2017).

Delgado, Manuel, 1999, El animal público, Anagrama, Barcelona.

Harvey, David. 2008, "La libertad de la ciudad", Antipoda, núm. 7 , julio-diciembre, pp. 15-29. Disponible en: http://www.redalyc. org/pdf/814/81411812003.pdf (Consultado: 23/XIII/2017).

Jiménez, Rogelio, 2010, "Ser gay en la ciudad de México". Letras Históricas, núm. 10, pp. 259-263. Disponible en: www.revistas- 
cientificas.udg.mx/index.php/LH/article/download/1835/1617 (Consultado: 20/IX/2017).

Lefebvre, Henri, 1978, De lo rural a lo urbano, Península, Barcelona.

Martínez, Emilio, 1999, "Introducción”, en La ciudad y otros ensayos de la ecología humana, Ediciones del Serbal, Barcelona.

Monsiváis, Carlos, 2002a, "Los gays en México: la fundación, la ampliación, la consolidación del ghetto", Debate Feminista, año 13, vol. 26, pp. 89-115. Disponible en: http://www.debatefeminista.pueg.unam.mx/wpcontent/uploads/2016/03/articulos/026_04.pdf (Consultado: 19/IX/2017).

,2002b, "Prólogo", La estatua de sal, Conaculta, México.

Naime, Alexander, 2007, Ciudad Invisible, Instituto Mexiquense de Cultura, México.

Novo, Salvador, 2002, La estatua de sal, Conaculta, México.

Park, Ezra. 1999, La ciudad y otros ensayos de la Ecología Humana, Ediciones del Serbal, Barcelona.

Rivera, Fernando, 1987, El urbanita: politica y urbanismo, SEP, México.

S/a, 1986, Diccionario Porrúa de historia, biografía, y geografía de México, Porrúa, México.

Zimmerman, Marc, 2003, "Fronteras latinoamericanas y las ciudades globalizadas en el nuevo (des)orden mundial", Universitas Humanística, núm. 53, junio, pp. 29-51. Disponible en: http://www.redalyc.org/articulo.oa?id=79105603 (Consultado: 23/XIII/2017). 